\title{
Dialética, totalidade e a gênese do pensamento moriniano: Uma breve análise
}

\author{
Dialectics, totality and the genesis of morinian thought: A brief analysis \\ Dialectica, totalidad y la genesis del pensamiento moriniano: Un breve analisis
}

Recebido: 01/05/2021 | Revisado: 07/05/2021 | Aceito: 08/05/2021 | Publicado: 22/05/2021

Marcos Fábio Teixeira Lopes
ORCID: https://orcid.org/0000-0003-2939-4317
E-mail: marcos.fabio21 @ gmail.com
Jefferson Queiroz Lima
Instituto Federal de Educação, Ciência e Tecnogia do Ceá, Brasil
ORCID: https://orcid.org/0000-0002-3250-1411
E-mail: jeffersonlima@ifce.edu.br
Pedro Bruno Silva Lemos
Instituto Federal de Educação, Ciência e Tenologia do Ceará, Brasil
ORCID: https://orcid.org/0000-0001-7235-9846
Eniversidade da Integração Internacional da Lusofonia Afro-Brasileira, Brasil
E-mail: pedrobruno_lemos@ yahoo.com.br

\begin{abstract}
Resumo
No prefácio do livro "Introdução ao Pensamento Complexo", escrito em 1990, Edgar Morin aborda as principais ilusões que afastam os espíritos da problemática do pensamento complexo. Nesse sentido, o presente artigo discute a relação teórica existente entre a dialética, tanto hegeliana como marxista, visualizando a noção de totalidade e a teoria da complexidade desenvolvida por Edgar Morin. $\mathrm{O}$ trabalho foi realizado por meio de pesquisa bibliográfica em artigos científicos, livros e demais documentos que abordam o tema. Traz em seu bojo, pensamento de autores como Konder (1984), Loureiro (2012), Lukács (1989) e o próprio Morin (2005), dentre outros. Conclui-se o trabalho comprovando que a complexidade suplanta a noção de totalidade por meio da presença da dialógica no pensamento moriniano. Diferentemente da dialética marxiana e da hegeliana, constatou-se que a dialética para Morin não é concebida como um método que pretende explicar fenômenos, mas discute o pensamento complexo demonstrando um continuo diálogo com as incertezas do mundo.
\end{abstract}

Palavras-chave: Dialética; Totalidade; Edgar Morin; Teoria da complexidade.

\begin{abstract}
In the preface to the book "Introduction to Complex Thinking", written in 1990, Edgar Morin addresses the main illusions that keep spirits away from the problem of complex thinking. In this sense, this article discusses the theoretical relationship between dialectic, both Hegelian and Marxist, visualizing the notion of totality and the theory of complexity developed by Edgar Morin. The work was carried out through bibliographic research in scientific articles, books and other documents that address the theme. It brings with it the thoughts of authors such as Konder (1984), Loureiro (2012), Lukács (1989) and Morin (2005), among others. The work is concluded by proving that complexity supersedes the notion of totality through the presence of dialogic in Morinian thought. Unlike Marxian and Hegelian dialectics, it was found that the dialectic for Morin is not conceived as a method that aims to explain phenomena, but discusses complex thinking by demonstrating a continuous dialogue with the uncertainties of the world.
\end{abstract}

Keywords: Dialectic; Totality; Edgar Morin; Theory of complexity.

\section{Resumen}

En el prefacio del libro "Introducción al pensamiento complejo", escrito en 1990, Edgar Morin aborda las principales ilusiones que mantienen a los espíritus alejados del problema del pensamiento complejo. En este sentido, este artículo discute la relación teórica entre la dialéctica, tanto hegeliana como marxista, visualizando la noción de totalidad y la teoría de la complejidad desarrollada por Edgar Morin. El trabajo se realizó a través de la investigación bibliográfica en artículos científicos, libros y otros documentos que abordan el tema. Trae consigo el pensamiento de autores como Konder (1984), Loureiro (2012), Lukács (1989) y Morin (2005), entre otros. El trabajo se concluye demostrando que la complejidad reemplaza la noción de totalidad a través de la presencia de dialógico en el pensamiento moriniano. A diferencia de la dialéctica marxista y hegeliana, se encontró que la dialéctica de Morin no se concibe como un método que pretende explicar fenómenos, sino que discute el pensamiento complejo demostrando un diálogo continuo con las incertidumbres del mundo.

Palabras clave: Dialéctica; Totalidad; Edgar Morin; Teoría de la complejidad. 


\section{Introdução}

A etimologia da palavra dialética origina-se do grego dialektiké, onde o prefixo "dia", expressa a ideia de dualismo, troca, e "lektikós", apto à palavra. Compartilha, portanto o mesmo radical de "logos", que é palavra, razão, com isso assemelha-se ao conceito de diálogo.

Epistemologicamente, a dialética como conhecemos, é uma redução de um conceito mais amplo, o método dialético, este se dá como uma maneira de estabelecer as argumentações do discurso, comumente entre dois ou mais sujeitos, que possuem pontos de vistas distintos a respeito de um mesmo assunto. Contudo, ambos os sujeitos buscam estabelecer, o que de fato é a verdade, mediante a fundamentação de seus argumentos, com isso, não há a intenção de estabelecer vencedores para esse debate ou persuadir o opositor. Embora o ato em si seja fundamental na formação da filosofia, o termo foi popularizado apenas com o advento dos diálogos socráticos de Platão.

Diante desse contexto, apresenta-se nesse estudo o pensamento dialético em sua gênese, quase que simultaneamente com a gênese da filosofia, a partir do estudo dos gregos, na antiguidade clássica, sendo sufocada no período medieval, ressurgindo com o Renascimento, perpassando pelo Iluminismo e atingindo seu ápice no mundo pós-moderno com Revolução Francesa, primeiro, com Hegel e, em seguida, com Marx.

Vale saliente que este trabalho analisa o pensamento de Morin baseado em diversos autores, marxistas ou não, que desenvolveram estudos por meio do método dialético. A perspectiva da dialética marxista, entretanto, tem como principal característica o reconhecimento do conhecimento totalizante, porém nunca definitivo e acabado. Como em Hegel, Marx entende que o conhecimento é tido como inacabado e não totalizante, nesse sentido, verificou-se que a teoria da complexidade pressupõe o reconhecimento da incompletude e da incerteza de qualquer explicação ou interpretação da realidade. Por isso, verificou-se, no estudo, que a visão marxiana da dialética influenciando diversos autores e correntes teóricas, pois, a partir desta, tornou-se possível compreender a realidade como algo mais rico e complexo relacionado ao conhecimento produzido.

Diante do exposto, o artigo discute, a partir de uma análise bibliográfica, a relação teórica existente entre a dialética, tanto hegeliana com marxista, visualizando a noção de totalidade e a teoria da complexidade desenvolvida por Edgar Morin, observando, de acordo com Konder (1984), que a dialética marxista pressupõe que a totalidade não é apenas a somas das partes.

\section{Metodologia}

Segundo Minayo (2002, p.44) a metodologia do trabalho científico, é definida:

(...) como a discussão epistemológica sobre o "caminho do pensamento" que o tema ou o objeto de investigação requer; b) como a apresentação adequada e justificada dos métodos, técnicas e dos instrumentos operativos que devem ser utilizados para as buscas relativas às indagações da investigação; c) e como a "criatividade do pesquisador", ou seja, a sua marca pessoal e específica na forma de articular teoria, métodos, achados experimentais, observacionais ou de qualquer outro tipo específico de resposta às indagações específicas.

Nesse sentido, o presente trabalho é classificado metodologicamente como uma pesquisa bibliográfica pautada em uma abordagem de cunho qualitativo. Segundo Gil (2008), na pesquisa bibliográfica a análise é desenvolvida em obras que receberam tratamento analítico durante sua feitura, ou seja, artigos científicos, livros, teses e dissertações.

Considerando que o presente artigo possui o objetivo analisar a importância da dialética e da noção de totalidade no pensamento moriniano, essa pesquisa bibliográfica foi pautada na análise de artigos científicos e nas obras de alguns autores, além de Edgar Morin, que discute a temática analisada. 
Outro fator também abordado neste trabalho trata-se do entendimento da epistemologia da dialética, compreendendo o estudo como uma obra científica que trabalha o todo, articulando diversos fatores, que dão unidade de sentido. Neste caso, o sentido se produz através de condições históricas e sociais que além de determinar fatos, caracterizam como única e como parte o processo maior de produção do conhecimento humano (Gamboa, 2012, p.56).

É importante mencionar que a escolha pela abordagem qualitativa justificou-se pela falta de aprofundar os "aspectos da realidade que não podem ser quantificados, centrando-se na compreensão e explicação da dinâmica das relações sociais" (Silveira \& Cordova, 2009, p. 32). Ademais, este tipo de abordagem "trabalha universo de significados, motivos, aspirações, crenças, valores e atitudes, o que corresponde a um espaço mais profundo das relações, dos processos e dos fenômenos que não podem ser reduzidos à operacionalização de variáveis" (Minayo, 2002, p. 21-22).

\section{Resultados e Discussão}

\subsection{A história da dialética e a relação com a totalidade}

Ao historicizarmos as concepções da dialética filosófica, temos que, segundo Konder, o fundador do Liceu, Aristóteles (384 - 322 a.C.), atribuía a Zênon de Eleia (490-430 a.C.) a criação da dialética. No entanto, outros pensadores consideram que Sócrates (469-399 a.C) foi o fundador desta maneira interpretativa. Provavelmente, o fato de Sócrates liderar os principais debates sobre a função da filosofia, dar-se pelo fato de Sócrates provocar os generais Lachés (475 - 418 a.C) e Nícias (470 a.C. - 413 a.C.) para que estes definissem os conceitos de bravura e inquiriu o sofista Caliclés (483- 484a.C) a definição do que era a política e a justiça.

O intuito de Sócrates era demonstrar que somente a filosofia, por intermédio da dialética, poderia proporcionar-lhes os argumentos imprescindíveis para que entendessem ontologicamente a natureza daquilo que eles faziam, bem como compreender as atividades profissionais a que se dedicavam.

Todavia, Konder (1984) argumenta que, na compreensão moderna vigente, a [...] dialética significa outra coisa: é o modo de pensarmos as contradições da realidade, o modo de compreendermos a realidade como essencialmente contraditória e em permanente transformação (Konder, 1984, p. 7 - 8).

Mais uma vez recorre-se a Konder (1984) para que se possa compreender que no sentido moderno da palavra dialética, o dialético mais radical da Grécia antiga foi, indubitavelmente, Heráclito de Efeso (540-480 a.C.). Heráclito deixou alguns escritos de maneira fragmentada, porém é possível interpretar de seus manuscritos a ideia de que tudo que existe está em permanente transformação, que o conflito é o cerne de todas as coisas. O fragmento mais famoso atribuído a Heráclito é aquele em se lê que um homem não toma banho duas vezes no mesmo rio, pois da segunda vez não será o mesmo homem e nem estará se banhando nas águas do mesmo rio, ambos terão mudado.

Os contemporâneos de Heráclito consideraram-no obscuro em suas explicações, e encontraram em Parmênides (530 a.C. - 460 a.C.), a contraposição ideal, pois para Parmênides, o âmago do ser é imutável, assim como, afirmava que que o movimento de mudança era um fenômeno de superfície. Essa corrente de pensamento deu início à chamada metafísica, sendo que esta prevaleceu sobre a dialética de Heráclito.

A Idade Média marca o apogeu do pensamento metafísico. Por quase um milénio, a ideologia dominante foi a teologia cristã, fato este que dificultou o progresso da dialética, uma vez que, interessava à Igreja, que os fiéis acreditassem em ideais estáticas, consolidadas, irretocáveis. Nesse período temos as bulas papais que determinavam os dogmas a serem seguidos, a santa inquisição que garantia que dissidentes não proliferassem ideias contrárias ao preestabelecido pela Santa Sé. Tal conjuntura propiciou o desenvolvimento da filosofia patrística e da escolástica, e ambas prescindiram do método dialético.

Na Europa, aproximadamente entre meados do século XIV e o fim do século XVI, o movimento Renascentista provocou mudanças culturais, intelectuais e artísticas literalmente, o pensamento nasceu novamente. Os renascentistas ao 
analisarem a dinâmica, da instabilidade e da contradição da natureza humana, colocaram em xeque as concepções metafísicas, dando novo fôlego ao pensamento dialético. Nesse sentido, Konder (1984) explica que:

Com o Renascimento, a dialética pôde sair dos subterrâneos em que tinha sido obrigada a viver durante vários séculos: deixou o seu refúgio e veio à luz do dia. Conquistou posições que conseguiu manter nos séculos seguintes. (Konder, 1984, p. 13).

Percebe-se que a contraposição entre a dialética e a metafísica, privilegiou esta última, pois as elites dominantes buscavam a manutenção do status quo, o que era fundamental para a manutenção de sistemas sociais estratificados. Tais sistemas perpassaram desde Ágora grega até os movimentos revolucionários do século XVIII. Sobre tal questão, Konder (1984) ressalta que:

De maneira geral, independentemente das intenções dos filósofos, a concepção metafísica prevaleceu, ao longo da história, porque correspondia, nas sociedades divididas em classes, aos interesses das classes dominantes, sempre preocupadas em organizar duradouramente o que já está funcionando, sempre interessadas em "amarrar" bem tanto os valores e conceitos como as instituições existentes, para impedir que os homens cedam à tentação de querer mudar o regime social vigente. (Konder, 1984, p. 9).

Durante o século XVIII, a disputa entre a metafísica e a dialética, ganhou novos contornos. Um dos maiores pensadores metafísicos modernos foi alemão Immanuel Kant (1724-1804). Kant percebeu na consciência humana, que esta não se limitava apenas ao mero registro passivo das impressões oriundas do mundo exterior, assim ela é sempre a consciência de um ser que interfere ativamente sobre a realidade. Ao observar isso, Kant, que era um metódico conhecido, percebeu que essa circunstância, complicava os processos do conhecimento humano. Coube a ele sustentar que todas as filosofias até aquela época, ou vinham sofrendo por sua ingenuidade ou estavam eivadas pelos dogmatismos, uma vez que, estas se propunham a interpretar o que era a realidade, antes mesmo de ter definido o que é o conhecimento. Acerca dos estudos kantianos sobre a consciência humana, Konder (1984) aponta que:

O Centro da filosofia, para Kant, não podia deixar de ser a reflexão sobre a questão do conhecimento, a questão da exata natureza e dos limites do conhecimento humano. Fixando sua atenção naquilo que ele chamou de "razão pura", o filósofo se convenceu, então, de que na própria "razão pura" (anterior à experiência) existiam certas contradições as "antinomias" - que nunca poderiam ser expulsas do pensamento humano por nenhuma lógica. (Konder, 1984, p. 20).

A hegemonia da metafísica, além de limitar a concepção dialética, a relegou posições secundárias, contudo esta não desapareceria. Para coexistir, a dialética precisou conciliar-se com a metafísica, abrindo mão de parte de seu radicalismo, entretanto, esse passo foi fundamental para que ainda se mantivessem abertos alguns espaços significativos nas ideias de diversos filósofos relevantes, tais como alemão Georg Wilhelm Friedrich Hegel (1770 - 1831).

Hegel sustentava que a questão central da filosofia deveria ser a questão do ser e não a do conhecimento, e aqui temos a contraposição de Kant e Hegel. Konder (1984) explica que Hegel fundamenta seus argumentos contra os de Kant, sintetizados na célebre frase "Se eu pergunto o que é o conhecimento, já na palavra é está em jogo certa concepção de ser; a questão do conhecimento, daquilo que o conhecimento é só pode ser concretamente discutida a partir da questão do ser".

Apesar das discordâncias entre Hegel e Kant, ambos concordavam com um ponto fundamental: os dois reconheciam que o humano é essencialmente ativo e está sempre interferindo e interagindo com a realidade.

Durante a Revolução Francesa de 1789, o jovem Hegel, vendo a tomada da Bastilha pelas mãos da plebe, a derrubada de instituições que até então pareciam imperecíveis, chegou a demonstrar seu entusiasmo com os movimentos de mudança, ao 
plantar uma árvore na cidade onde morava, em homenagem à França, sendo esta conhecida como a árvore da liberdade. Tanto Kant, quanto Hegel viram que aquele momento era marcado pela ratificação do poder humano, em detrimento das instituições seculares, tais como a monarquia absolutista.

Entre 1792 a 1794, Hegel se decepcionaria com aquela Revolução, após os jacobinos começarem o massacre de monarquistas, e a guilhotina ser usada como instrumento da justiça para os plebeus. Segundo Konder (1984) "Hegel descobriu, então, com amargura, que o homem transforma ativamente a realidade, mas quem impõe o ritmo e as condições dessa transformação ao sujeito é, em última análise, a realidade objetiva".

Na obra Ciência da Lógica, Hegel estabelece que a dialética se desenvolve e se estrutura como pensamento de uma maneira objetiva. Com isso, a fundamentação da dialética toma caminhos diferenciados junto ao materialismo, o assim chamado, "materialismo dialético". O francês Jean Paul Sartre expõe em sua obra Crítica da Razão Dialética, sua concordância com a interpretação da dialética como elemento substancial da realidade histórica, corroborando esta não só como mera renovação da dialética materialista, pois tratar-se de novas formulações a crítica ao idealismo Hegeliano.

O processo de desencantamento de Hegel dá ênfase ao desenvolvimento de uma concepção de superação da dialética. Para ele, um idealista, os movimentos da realidade material estavam subordinados à lógica de um princípio que ele chamava de Ideia Absoluta. Conceitualmente, a Ideia Absoluta era um princípio inexoravelmente nebuloso, turvo, opaco, onde os movimentos da realidade material eram descritos pelo filósofo de maneira bastante vaga. Esse idealismo, e as visões sobre o trabalho com elemento primordial, abriu caminho para outro pensador alemão que influenciaria sobremaneira a concepção contemporânea de dialética, Karl Marx (1818 - 1883).

Hegel percebe que o trabalho é a mola que impulsiona o desenvolvimento humano; é no trabalho que o homem se produz a si mesmo; o trabalho é o núcleo a partir do qual podem ser compreendidas as formas complicadas da atividade criadora do sujeito humano. No trabalho se encontra tanto a resistência do objeto (que nunca pode ser ignorada) como o poder do sujeito, a capacidade que o sujeito tem de encaminhar, com habilidade e persistência, uma superação dessa resistência. (Konder, 1984, p. 24).

A seara aberta por Hegel foi ocupada por Marx, e o idealismo hegeliano deu lugar ao pensamento materialista. Há para muitos pensadores a superação, dialeticamente, de Marx sobre Hegel. Coube a Marx, escrever que em Hegel a dialética estava de cabeça para baixo, invertida. Enquanto Hegel era um notório intelectual enclausurado em bibliotecas, o jovem Marx, logo cedo se vinculou ao movimento operário e socialista, posicionando-se politicamente junto aos trabalhadores, sendo exilado na Inglaterra, em 1849, onde pode ver de perto as consequências da Revolução Industrial. Essas experiências em realidades tão distintas seriam determinantes para os novos rumos da dialética.

Assim como ocorreu com Kant, agora Hegel era desconstruído pelas ideias de Marx. No entanto, Marx concordou integralmente com a observação de Hegel de que o trabalho era a mola que impulsionava o desenvolvimento humano, porém criticou a forma unilateral da concepção hegeliana de trabalho, a qual dava importância demais ao trabalho intelectual e não enxergava a significação, relevância social ao trabalho físico, braçal, material.

"O único trabalho que Hegel conhece e reconhece" - observou Marx em 1844 - "é o trabalho abstrato do espírito." Essa concepção abstrata do trabalho levava Hegel a fixar sua atenção exclusivamente na criatividade do trabalho, ignorando o lado negativo dele, as deformações a que ele era submetido em sua realização material, social. Por isso Hegel não foi capaz de analisar seriamente os problemas ligados à alienação do trabalho nas sociedades divididas em classes sociais (especialmente na sociedade capitalista). (Konder, 1984, p. 27).

Marx, afirma que o trabalho é a atividade pela qual o homem domina as forças naturais, humaniza a natureza, é a atividade pela qual o homem se cria a si mesmo. Com isso ele questiona como, o trabalho, de condição natural para a 
realização do homem, chegou ao ponto de tornar-se algoz dos homens? Chegou a se transformar em "uma atividade que é sofrimento, uma força que é impotência, uma procriação que é castração". As respostas às perguntas de Marx, são por ele elucidadas, ao afirmar como causas: a divisão social do trabalho, a apropriação privada das fontes de produção e o aparecimento das classes sociais. No ideário marxista, alguns poucos homens passaram a dispor de meios para explorar o trabalho dos outros, passando com isso, a impor aos trabalhadores condições de trabalho que não eram livremente assumidas por estes até então. Foi introduzido, assim, um novo tipo de contradição no interior da sociedade e, por conseguinte, no interior do gênero humano. Com isso, Marx estabelece um novo marco, o materialismo histórico-dialético.

Na perspectiva da dialética marxista, o conhecimento é totalizante, assim como a atividade humana, de modo geral, dá-se de forma a integrar-se a esse processo de totalização, que nunca alcança uma etapa definitiva e acabada. Hegel já havia dito que "A verdade é o todo". Ao não enxergarmos o todo, podemos atribuir um valor desproporcional a uma verdade limitada, com isso maculando-a, transformando-a em mentira, prejudicando assim, a nossa compreensão de uma verdade mais ampla:

Qualquer objeto que o homem possa perceber ou criar é parte de um todo. Em cada ação empreendida, o ser humano se defronta, inevitavelmente, com problemas interligados. Por isso, para encaminhar uma solução para os problemas, o ser humano precisa ter uma certa visão de conjunto deles: é a partir da visão do conjunto que podemos avaliar a dimensão de cada elemento do quadro. (Konder, 1984, p. 35).

Dentro da visão marxista, a realidade é sempre mais rica do que o conhecimento que temos dela. Temos que ter em mente que existirá sempre algo que escapa às nossas conclusões, isso, porém, não nos dispensa do esforço de elaborar novas sínteses, se realmente quisermos entender melhor essa realidade. De certo modo, a síntese é uma visão de todo conjunto, o que permite ao sujeito (re) descobrir a estrutura e os significados da realidade com que se defronta. A essa estrutura significativa, que é a visão do conjunto, dá-se o nome de totalidade, isto é:

A totalidade é mais do que a soma das partes que a constituem. No trabalho, por exemplo, dez pessoas bem entrosadas produzem mais do que a soma das produções individuais de cada uma delas, isoladamente considerada. Na maneira de se articularem e de constituírem uma totalidade, os elementos individuais assumem características que não teriam, caso permanecessem fora do conjunto. (Konder, 1984, p. 36).

A totalidade pode ser dividida em mais abrangentes ou menos abrangentes. As menos abrangentes, por conseguinte, fazem parte das outras. Tem-se que a maior ou menor abrangência de uma totalidade depende do nível de generalização do pensamento dos objetivos concretos dos homens em cada situação dada. Pensar a realidade social do país requer um pensamento complexo, mas menos abrangente do que pensar a situação social do continente como um todo, por exemplo:

Para trabalhar dialeticamente com o conceito de totalidade, é muito importante sabermos qual é o nível de totalização exigido pelo conjunto de problemas com que estamos nos defrontando; e é muito importante, também, nunca esquecermos que a totalidade é apenas um momento de um processo de totalização (que, conforme já advertimos, nunca alcança uma etapa definitiva e acabada). Afinal, a dialética - maneira de pensar elaborada em função da necessidade de reconhecermos a constante emergência do novo na realidade humana - negar-se-ia a si mesma, caso cristalizasse ou coagulasse suas sínteses, recusando-se a revê-las, mesmo em face de situações modificadas. (Konder, 1984, p. 38).

Após Marx, outros pensadores deram suas contribuições ao estudo da dialética, destaca-se Georg Lukács (1885-1971), pensador marxista húngaro, que em sua obra História e Consciência de Classe, tentou edificar duas teorias: a teoria do desenvolvimento da consciência da classe trabalhadora como classe revolucionária. Bem como, buscou reconstruir na dialética marxista a relação desta com o idealismo alemão e como superação das "antinomias do pensamento burguês", estabelecendo uma ideia de "ortodoxia" marxista, centrada na questão do método. 
Acerca da importância da categoria de totalidade no pensamento marxista, Lukács (1989) aponta que:

Não é o predomínio de motivos econômicos na explicação da história que distingue de maneira decisiva o marxismo da ciência burguesa, mas o ponto de vista da totalidade. A categoria da totalidade, o domínio do universal e determinante do todo sobre as partes constituem a essência do método que Marx recebeu de Hegel e transformou de maneira original no fundamento de uma ciência inteiramente nova. [...] A ciência proletária é revolucionária não somente pelo fato de contrapor à sociedade burguesa conteúdos revolucionários, mas, em primeiro lugar, devido à essência revolucionária de seu método. O domínio da categoria da totalidade é o portador do princípio revolucionário da ciência (Lukács, 1989).

Portanto, Lukács (1989) ressalta que a categoria da totalidade assume um papel central no desenvolvimento da ciência proletária, pois proporciona o entendimento de como os aspectos universais determinam e condicionam as partes, ideia fundamental para o desenvolvimento do método que Marx recebeu de Hegel, isto é, o método dialético.

\subsection{Entendendo a dialética e totalidade em Edgar Morin}

A Teoria da Complexidade foi criada e sistematizada por Edgar Morin, pensador com relevante atuação em diferentes campos de conhecimento, nos primeiros anos da década de 1970 (Pires \& Rigue, 2020). A proposta teórica moriniana pressupõe o reconhecimento da complexidade dos fenômenos e ressalta a limitação resultante de qualquer proposta de simplificação da realidade. Cabe mencionar que a Teoria da Complexidade proporcionou e proporciona profícuos debates em diversas áreas de conhecimento, especialmente, nas áreas de Epistemologia e Educação (Arruda; Soave \& Rosa, 2020; Lemos, Aquino, Silva, Jucá, Medeiros da Silva \& Freitas, 2019; Pires \& Rocha Veiga, 2020; Rodrigues \& Boer, 2019).

Edgar Morin relata duas principais ilusões que afastam os espíritos da problemática do pensamento complexo. A primeira grande ilusão é entender a complexidade como destruição da simplicidade. Acerca de tal questão, Morin (2001) esclarece que a complexidade procura a integração dos modos simplificadores de pensar, porém recusando todas as consequências reducionistas do processo de simplificação da realidade. Nas palavras do autor:

A complexidade aparece certamente onde o pensamento simplificador falha, mas integra nela tudo o que põe ordem, clareza, distinção, precisão no conhecimento. Enquanto o pensamento simplificador desintegra a complexidade do real, o pensamento complexo integra o mais possível os modos simplificadores de pensar, mas recusa as consequências mutiladoras, redutoras, unidimensionais e, finalmente, ilusórias de uma simplificação que se toma pelo reflexo do que há de real na realidade. (Morin, 2001, p. 9)

A segunda ilusão apontada por Morin refere-se à compreensão da complexidade como sinônimo de completude. O autor ressalta que o pensamento complexo ambiciona compreender as articulações existentes entre os campos de conhecimento que foram dissolvidas pelo pensamento simplificador, porém esta ambição não deve ser confundida como uma busca pela onisciência. O pensamento complexo, dessa forma, “[...] sabe desde o começo que o conhecimento completo é impossível: um dos axiomas da complexidade é a impossibilidade, mesmo em teoria, de uma onisciência" (Morin, 2001, p. 9).

Ao citar Theodor W. Adorno, para quem qualquer forma de totalidade deve ser compreendida como uma não verdade, Morin (2001) explica que a teoria da complexidade desde sua gênese pressupõe o reconhecimento da incompletude e da incerteza do conhecimento. Entretanto, o autor também frisa que o pensamento complexo "tem em seu princípio o reconhecimento dos laços entre as entidades que nosso pensamento deve necessariamente distinguir, mas não isolar umas das outras" (Morin, 2001, p. 9).

Em termos epistemológicos, Lemos et at (2019) salienta que o pensamento complexo é desenvolvido a partir de uma contínua tensão entre a busca por um saber não fragmentado, sem compartimentalização, sem reduções da realidade, e a 
compreensão do inacabamento e da incompletude de todo conhecimento. Conforme aponta Edgar Morin na obra "Ciência com Consciência":

Acontece que o problema da complexidade não é o da completude, mas o da incompletude do conhecimento. Num sentido, o pensamento complexo tenta dar conta daquilo que os tipos de pensamento mutilante se desfaz, excluindo o que eu chamo de simplificadores e por isso ele luta, não contra a incompletude, mas contra a mutilação (Morin, 2005, p. 176).

A inserção da compreensão do inacabamento e da incompletude de toda forma conhecimento no pensamento moriniano está intrinsecamente relacionada à influência da dialética marxista e hegeliana na gênese da teoria da complexidade, o que fica evidente pela utilização e significação do conceito de totalidade na obra do mencionado autor (Corrêa, \& Castro 2013; Piqueira, 2018; Santos \& Hammerschmidt, 2012).

Loureiro e Viégas (2007; 2012), Piva (2005) e Pena-Veja, Almeida e Petraglia (2003) apontam que o pensamento de Edgar Morin pode ser classificado em três fases com distintas características. A primeira fase, que vai do início da década de 1940 até o início da década de 1970, é caracterizada pela forte influência e inserção de conceitos e categorias marxistas no pensamento moriniano.

A segunda fase tem como principal característica o desenvolvimento do método do autor. É no período entre o início dos anos de 1970 e o final da década de 1980 que ocorre a incorporação da teoria dos sistemas, da cibernética, da teoria da informação e das discussões oriundas da termodinâmica na obra do autor. Também ocorre um maior afastamento da dialética marxista e a aproximação de autores que discutem a dialógica (Loureiro \& Viégas, 2007).

A terceira fase que tem seu início nos primeiros anos da década de 1990 é caracterizada pela consolidação da teoria da complexidade com um maior privilégio à dialógica, bem como ao acentuado debate acerca da educação e uma maior publicização do pensamento moriniano por meio de textos com caráter mais didático.

Na obra "Meus demônios", sua autobiografia intelectual, Edgar Morin (1997) detalha a importância de Hegel para o desenvolvimento do seu pensamento. Para o autor, a dialética hegeliana possibilitou a compreensão de que a totalidade está sempre inacabada, isto é, a verdade encontra-se sempre em um processo de "reconstrução".

Hegel me revela uma visão da verdade que respondia a minha necessidade: era falsa toda idéia fechada, cristalizada, abstrata, separada da totalidade de que faz parte; mas toda idéia falsa era verdadeira, na medida em que exprimia uma parcela da totalidade. A verdade era a totalidade, mas como a totalidade estava sempre em movimento, sempre inacabada, a verdade estava em marcha ininterrupta, fazendo-se e desfazendo-se. (Morin, 1997, pp. 56 e 57).

Ao discutir a importância de Hegel na gênese do pensamento complexo, Albuquerque, Medeiros, Luna, Almeida \& Felisberto (2012, p. 504) ressaltam que a dialética hegeliana permitiu a Edgar Morin descobrir que "a contradição estava no fundamento do ser". O próprio Morin (1997) coloca que a leitura de Hegel permitiu-lhe ter acesso a um núcleo de ideais fundamentais, bem como extrair os aspectos essenciais da dialética marxiana.

Loureiro e Viégas (2007) afirmam que, durante as duas primeiras fases do pensamento moriniano, a compreensão da totalidade da realidade aproxima Morin de Marx, porém nestas fases há também duras críticas às apropriações de Marx comuns ao cenário intelectual francês na segunda metade do século XX, o que pode ser observado quando mesmo afirma que:

O que caracterizou o método de Marx foi um espírito crítico radical ilimitado, um pensamento dialético sempre em movimento, foi privilegiar o movimento em oposição à essência enrijecida ou reificação. Em todo o sistema marxista vê-se aparecer uma tendência à estruturação, à imobilização, que pode conduzir à esclerose, à petrificação e, em casos extremos, mas freqüentes, à fetichização em dogmas religiosos. (Morin, 2002, p. 74). 
No decorrer da sua autobiografia, Morin aponta a importância da influência hegeliana e marxista no seu pensamento, destacando a retoma do conceito de totalidade na gênese do seu pensamento complexo. Todavia, o autor coloca que a complexidade suplanta a totalidade, pois:

[...] a presença da dialógica da ordem e da desordem mostra que o conhecimento deve tentar negociar com a incerteza. Isso significa ao mesmo tempo que o objetivo do conhecimento não é descobrir o segredo do mundo ou a equaçãochave, mas dialogar com o mundo". (Morin, 2005, p. 205).

Portanto, segundo Loureiro \& Viégas (2007, p. 21), "Morin não nega a dialética marxiana, mas a incorpora na ideia da dialógica, que traz, em seu bojo, a abertura para a autorreflexão do conhecimento humano". O pensamento complexo, dessa forma, busca:

[...] reconhecer os traços singulares, originais, históricos do fenômeno em vez de ligá-los pura e simplesmente a determinações ou leis gerais, a conceber a unidade-multiplicidade de toda a entidade em vez de a heterogeneizar em categorias separadas ou de homogeneizar numa totalidade indistinta. Incita a dar conta dos caracteres multidimensionais de toda a realidade estudada" (Morin, 2005 p. 334).

Para o pensamento moriniano, a unidade e heterogeneidade não devem ser compreendidas como características excludentes de explicação da realidade, pois “[...] é a dialética, a dialógica entre essas duas características que, também nesse caso, faz a vitalidade de uma atividade científica" (Morin, 2005 p. 53).

Nesse contexto, a análise crítica e bibliográfica realizada no presente artigo, evidenciou a importância da dialética hegeliana e marxista na gênese do pensamento moriniano. Entretanto, concluiu-se que a complexidade suplanta a noção de totalidade por meio da presença da dialógica no pensamento moriniano, ou seja, diferente da dialética marxiana e da hegeliana, Morin não pretende explicar fenômenos, pelo contrário, o pensamento complexo busca um continuo diálogo com a incerteza do mundo.

\section{Considerações Finais}

De acordo com os aspectos abordados nesse estudo, percebe-se que o pensamento complexo, baseado em Edgar Morin, não se opõe ao pensamento simplificado, mas o incorpora, e o paradigma da complexidade apresenta-se de modo tão simples, que se equipara a própria simplicidade, pois enquanto o pensamento simples impõe separar e reduzir, a complexidade preconiza reunir, ainda que se possa distinguir.

Percebe-se, no estudo, que fatores como ordem e desordem, articulam princípios de união e separação, muitas vezes até de dependência e autonomia, e podem se tornar complementares, concorrentes e antagônicos, ou seja, vislumbrou-se que o pensamento complexo é essencialmente um pensamento que incorpora a incerteza e é capaz de conceber a organização.

Verificamos, também, que Morin (2007, p.76) aborda que o pensamento complexo "é capaz de contextualizar e globalizar, e pode, ao mesmo tempo, reconhecer o que é singular e concreto", tornando-se momentos contínuos de incertezas, o que possibilita verificar o elementar e o geral, vinculando o concreto das partes à totalidade. "Não se trata de abandonar os princípios da ciência clássica, mas de integrá-los de um modo mais amplo e rico" (Morin, 2007, p. 62).

Portanto, nessa pesquisa bibliográfica, a leitura dos textos, permitiu acompanhar o raciocínio de Morin, analisando questões que não seria possível em outro contexto, pois seria, inclusive, considerado inimaginável, devido o autor evidenciar a importância da composição de saberes, de acordo com a relação do próprio contexto visualizando um mundo onde o todo é a soma das partes. 
Concluímos esse estudo, evidenciando que devemos sempre buscar o conhecimento através do próprio conhecimento, pois "o pensamento complexo não termina com o assombro", mas possibilita para os pesquisadores realizarem uma descoberta sobre a teoria complexa, analisando a abordagem sistêmica, como verdadeira realidade sobre a sistematicidade do todo, tornando as partes manifestações de algo mais complexo.

Dessa forma, Morin nos mostra que a complexidade pressupõe uma permanente relação dialógica entre aspectos tidos como antagônicos, em outras palavras, "a complexidade é uma noção lógica, que une o uno e multiplica-o em unitas multiplex do complexus, complementar e antagonista na unidade dialógica, ou, como querem alguns, na dialética”. Nesse interim, finalizando esse trabalho, o pensamento de Morin (2005 p. 55) coloca que "[...] todo desenvolvimento verdadeiramente humano significa o desenvolvimento conjunto das autonomias individuais, das participações comunitárias e do sentimento de pertencer à espécie humana".

Como proposta para futuros estudos, indica-se a necessidade de pesquisas acerca da noção de dialética nas obras mais recentes de Edgar Morin. Ademais, salienta-se a importância de trabalhos que discutam as possíveis semelhanças e diferenças epistemológicas existentes entre a Teoria da Complexidade e as noções de dialética presentes nas teorias hegelianas, a marxistas e a neohegelianas.

\section{Referências}

Albuquerque, M. D. S. V. D., Medeiros, K. R. D., Luna, K., Almeida, S. R. D., \& Felisberto, E. (2007). The expression of the demons of Morin. Revista Brasileira de Saúde Materno Infantil, 7(4), 503-506.

Arruda, M. P., Soave, C., \& Rosa, G. A. (2020). Auto-ética: um saber para ressignificar a docência. Research, Society and Development, 9(12), e20091211007-e20091211007.

Corrêa, G. R., \& Castro, M. L. A. (2013). O pensamento complexo de Edgar Morin e o design. Estudos em Design, 21(1).

Gamboa, Sílvio Sánchez Pesquisa em educação: métodos e epistemologias. (2a ed.), Argos.

Gil, A. C. (2008). Métodos e técnicas de pesquisa social. (6a ed.), Editora Atlas SA.

Hegel, G. W. F. (2016). Ciência da Lógica: 1. A Doutrina do Ser. Traduzido por Christian G. Iber, Marloren L. Miranda e Federico Orsini. Petrópolis, RJ: Vozes; Ed. Universitária São Francisco.

Konder, L. (1984). O que é dialética? (9a ed.) Brasiliense.

Lemos, P. B. S., de Aquino, F. J. A., da Silva, S. A., Jucá, S. C. S., da Silva, F. E. M., \& de Freitas, S. R. (2019). O conceito de paradigma em Thomas Kunh e Edgar Morin: similitudes e diferenças. Research, Society and Development, 8(10), e078101321-e078101321.

Loureiro, C. F. B., \& Viégas, A. (2012). Algumas considerações sobre as influências do marxismo na teoria da complexidade de Edgar Morin: aportes para a pesquisa em educação ambiental. AMBIENTE \& EDUCAÇÃ O-Revista de Educação Ambiental, 17(2), 13-24.

Lukács, G. (1989). História e consciência de classe: estudos de dialética marxista. Trad. Telma Costa; Revisão Manuel A. Resende e Carlos Cruz - $2^{\circ}$ Edição, Rio de Janeiro: Elfos Ed.; Porto, Portugal, Publicações Escorpião.

Minayo, M. C. S. (2002). Ciência, Técnica e Arte: o desafio da pesquisa social. In: Minayo, M.C.S. (ORG.). Pesquisa Social: Teoria, Método e criatividade. Petrópolis, RJ: Vozes, 09-29.

Morin, E. (1997). Meus demônios. Bertrand Brasil.

Morin, E. (2002). Em busca dos fundamentos perdidos - textos sobre o marxismo. Sulina.

Morin, E. (2005). Ciência com Consciência. (8a ed.), Bertrand Brasil.

Morin, E. (2007). Introdução ao pensamento complexo. (3a ed.), Sulina.

Pena-Veja, A., Almeida, C. R S., \& Petraglia, I. (2003). Edgar Morin: ética, cultura e educação. Cortez.

Petraglia, I. (2001). Olhar sobre o olhar que olha: complexidade, holística e educação. Vozes.

Pires, C. S., \& Rigue, F. M. (2020). Complexidade e escolarização: tramando tensionamentos. Research, Society and Development, $9(10)$, e6909109163e6909109163. 
Research, Society and Development, v. 10, n. 6, e10910615665, 2021

(CC BY 4.0) | ISSN 2525-3409 | DOI: http://dx.doi.org/10.33448/rsd-v10i6.15665

Pires, C. S., \& Rocha Veiga, A. M. (2020). Costurando possibilidades na complexidade da docência: a bricolagem na trajetória auto (trans) formativa. Research, Society and Development, 9(9), e20996496-e20996496.

Piqueira, J. R. C. (2018). Engenharia da Complexidade em Edgar Morin. Estudos Avançados, 32(94), 363-370.

Piva, A. (2005). A apropriação do pensamento de Edgar Morin na pesquisa em educação ambiental no Brasil. Dissertação de Mestrado, Mestrado em Educação, Faculdade de Educação da UFMG.

Rodrigues, J. D. S. M., \& Boer, N. (2019). Da epistemologia à prática docente na educação infantil: relato de uma sequência didática. Research, Society and Development, 8(6), e186969-e186969.

Santos, S. S. C., \& Hammerschmidt, K. S. D. A. (2012). A complexidade e a religação de saberes interdisciplinares: contribuição do pensamento de Edgar Morin. Revista Brasileira de Enfermagem, 65(4), 561-565.

Sartre, Jean-Paul (2002). Crítica da razão dialética: precedido por questões de método. Tradução de Ghilherme João de Freitas Teixeira; apresentação da edição brasileira, Gerd Bornheim. DP\&A, 2002.

Silveira, D. T., \& Córdova, F. P. (2009). Unidade 2 - A pesquisa científica. In: Métodos de pesquisa, 1. 